\title{
EDITORIAL
}

\section{AFTER TEN YEARS IN THE ALLIANCE}

At the beginning of the year, we announced that the third issue of the Contemporary Military Challenges would be dedicated to the tenth anniversary of the accession of the Republic of Slovenia to NATO. However, we did not expect such a good response. We received articles from authors who are very familiar with the history of Slovenia's efforts to join the Alliance; most of them were also personally involved in the process. Since they are still present and active in their professional fields, their views of the past events have a special personal character, while their views of the future are enriched by the theoretical knowledge and personal experience.

Unfortunately, we cannot publish all the articles we have received. The guiding principle in the selection was the focus on the defence and military contents, since we mainly wanted to pay attention to the contents to which this publication is dedicated and which are defined in its acts as its basic mission.

In 2009, we marked the fifth anniversary of Slovenia's membership in the Alliance and the sixtieth anniversary of the Alliance with a special thematic issue. The themes covered were very interesting for the countries of the South Eastern Europe which were treading the path that Slovenia had already travelled. We expect this issue to be of interest to people who like the defence and military themes, to younger generations and to all those who might still be on the road of approximating to or entering the Alliance. By reading the contents below, you can discover how successful we were in ensuring this interest.

The article titled NATO after 2014 - Back to the Roots or Forward towards the Future? by Uros Lampret and Staša Novak presents the Alliance today, the current security trends that are emerging in the world, and the responses to them. The authors claim that back to the roots or forward towards the future does not mean two different directions, but something completely different. 
In theoretical and practical terms, Milan Jazbec gives an overview of the Slovenian experiences at the time which constitutes the central theme of this issue. He uses the term "learning from experience", and the title of his article Slovenia and NATO: the Long and Winding Road is not merely symbolic.

Andrej Osterman prepared an overview of the operation of the Slovenian Armed Forces and its experiences within the Alliance. In the article titled Republic of Slovenia in NATO - Slovenian Armed Forces Ten Years Later, he presented the key changes and progress of the Slovenian military.

Damir Črnčec and Janez Urbanc focused on the intelligence and security area. In the article titled Streamlining the Intelligence and Security Structures in NATO and the European Union, the authors describe in detail the changes in the organization and the functioning of the intelligence and security community in the international environment, and also the role of Slovenia in it.

In his article titled Slovenia's Contribution to Afghanistan Peace and Reintegration Programme (APRP) - Policy Advisor's Perspective, Aljosa Selan presents the activities in Afghanistan after the gradual withdrawal of the Allied Forces, aimed at the best possible preparation of the country's residents for an independent and quality everyday life.

The Normative Role of the Alliance in Non-Conventional Security Threats - Cyber Defence of the Member States is the title of the article written by Adriana Dvoršak. The author raises topical issues which are changing so rapidly that the security structures are already aware of possible threats. There is much that still needs to be done in order to achieve effective protection.

We would like to thank all the authors for their work and efforts, especially for their willingness to share with us their knowledge, experiences and views.

We invite all those who might be thinking about preparing an article, but have not yet decided to do so, to send us their contributions.

Good luck! 